\title{
PERANCANGAN LISTRIK ENERGI SURYA 300VA, 220V, 50HZ, UNTUK RUMAH TANGGA SEDERHANA
}

\author{
SupraptoW $^{1,}$,,$J u l i$ Iriani ${ }^{2}$ \\ ${ }^{1}$ Jurusan Teknik Mesin, Teknik Konversi Energi \\ Politeknik Negeri Medan \\ ${ }^{2}$ Jurusan Teknik Elektro, Teknik Listrik \\ a suprapto_widodo482@yahoo.co.id; sptwdd482@gmail.com
}

\begin{abstract}
Abstrak
Pengadaan energi listrik untuk rumah tangga sederhana diantaranya adalah, masing 50Wp, 12V, 1.5A, panel surya dihubung parallel, tegangan luaran panel surya 12V, dan arus luaran hasilnya 4,5A. Pada saat matahari bersinar cerah, arus ini masuk ke Pengendali Pengisian, dan Sistem mampu melayani prioritas 7 unit lampu 3 W atau lampu 7W. Pada penelitian ini digunakan tiga lembar panel surya masing-diteruskan ke baterai, Pengendali Pengisian harus sanggup mengalirkan arus tersebut, maka dipilih Pengendali Pengisian dengan kemampuan 15A. Kalau matahari bersinar cerah seharian diambil data mulai jam 09.00 s/d 15.00 WIB, yaitu selama 6 jam, di baterai tersimpan energi 27Ah, dan dibutuhkan baterai $12 \mathrm{~V} 45 \mathrm{Ah}$ untuk 3 panel surya dan $12 \mathrm{~V}$, artinya hanya untuk penerangan saja, daya tersebut memadai, bila daya semu 300VA dan dianggap faktor daya adalah satu maka 300VA akan setara 300W. Kalau disisi beban atau keluaran inverter 300W, maka arus keluaran maksimum inverter sebesar 1.36A dan arus masukan inverter sekitar 25A, energi di baterai selama 6 jam akan 27Ah, sehingga energi di baterai bisa untuk pelayanan listrik selama 1,3 jam, agar bisa beroperasi selama 2,6 jam maka perlu pengadaan panel surya sebanyak 6 lembar, dengan kapasitas Pengendali Pengisian sekitar 15A, inverter 500W dan kapasitas baterai 60Ah, tapi dengan 6 lembar panel surya, dan Pengendali Pengisian 1 unit 15A, baterai 60Ah, inverter $500 \mathrm{~W}$, masukan $12 \mathrm{~V}$, luaran 220V, 50Hz. Rancangan ini disiapkan mampu untuk beban 300W. Untuk pelayanan beban 7 lampu masing-masing 3W sehinga total beban 21W. Arus per lampu 0,014A arus luaran inverter 0,09A tegangan luaran inverter 220V, arus masukan inverter 1,75A, tegangan masukan inverter 12V, energi listrik tersimpan di baterai 27Ah, kemampuan sistem melayani beban 15 jam lebih. Kalau digunakan lampu $7 \mathrm{~W}$ maka total 49W butuh arus masukan ke inverter 4A, maka beban mampu dilayani selama 6,5 jam.
\end{abstract}

Kata kunci: panel surya, pengendali pengisian, baterai, inverter, beban.

\section{PENDAHULUAN}

Dalam perencanaan perumahan sederhana dipinggir kota yang belum tercapai sumber listrik PLN terkendala tentang masalah penerangan rumah, biasanya jalan keluarnya adalah, penerangan dengan lilin, penerangan dengan minyak tanah, penerangan dengan minyak tanah bertekanan atau biasa disebut dengan petromax, penerangan dengan baterai kering, penerangan dengan genset, penerangan dengan mancis, penerangan dengan hand phone yang masing-masing dengan kendala yang mengkhawatirkan. Untuk mengatasi hal tersebut dilakukan penelitian produk terapan berupa, listrik energi surya $300 \mathrm{VA}, 220 \mathrm{~V}, 50 \mathrm{~Hz}$. Untuk hal tersebut dilakukan dengan tiga lembar panel surya dengan spesifikasi; $50 \mathrm{~W}, 12 \mathrm{~V}, 1.5 \mathrm{~A}, 55 \mathrm{cmx} 80 \mathrm{~cm}$. diletakkan di atap rumah, dibutuhkan juga Pengendali Pengisian dengan batas kapasitas 30A satu unit, satu unit baterai $12 \mathrm{~V}$, dengan kapasitas 45Ah atau 60Ah, satu unit inverter dengan kapasitas 500W. Dimaksud agar prioritas penerangan dapat terselenggara untuk 7 unit lampu penerangan $3 \mathrm{~W}$ × 7 unit dan $7 \mathrm{~W}$ × 7 unit, di masing-masing lokasi yang sudah ditentukan. Penerangan yang dilakukan adalah dengan lampu hemat energi yaitu lampu 3W dan 7W, 220V, LED, 860LM

Dengan penelitian produk terapan ini diharapkan akan;

a. Terhindar dari bahaya kebakaran,

b. Tidak perlu menyiapkan bahan bakar,

c. Energi matahari gratis dan tak terbatas,

d. Tidak ada polusi,

e. Tidak bising, dan aman perawatannya,

f. Mengurangi ketergantungan pada listrik pemerintah,

g. Mengurangi biaya listrik jangka panjang karena kebutuhan listrik seumur hidup,

h. Menghindari dampak pemadaman,

i. Turut mengurangi pemanasan global, karena ramah lingkungan, 
Demikian harapan setelah penelitian terapan ini dilakukan.

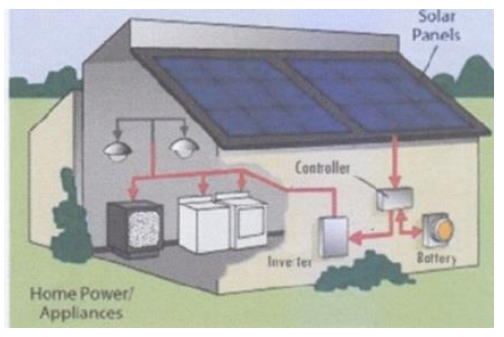

Gambar 1.1 : listrik energi surya

Energi surya yang menerpa panel surya, tegangan dan arusnya saat masuk ke baterai diukur dengan teliti. Tegangan yang ada di baterai dipantau terus menerus. Tegangan dan arus yang masuk ke inverter dipantau terus menerus. Tegangan dan arus yang masuk ke beban penerangan elektrik dipantau terus menerus dengan teliti. Data tersebut dianalisis sedemikian rupa yang nantinya digunakan sebagai simpulan dan saran.

Batasan masalah mencakup: panel surya $50 \mathrm{~W}, 220 \mathrm{~V}$, 1.5A tiga unit, satu unit pengendali pengisi baterai dengan kapasitas 30A,baterai $45 \mathrm{Ah}$ atau $60 \mathrm{Ah}$, satu unit inverter dengan kapasitas 500W.

1.Capaian penerangan tujuh lampu penerangan $3 \mathrm{~W}$ sebagai prioritas utama, total $21 \mathrm{~W}$, dan tujuh lampu penerangan $7 \mathrm{~W}$ total $49 \mathrm{~W}$.

2.Tahap awal dengan lampu $3 \mathrm{~W}$ dan tahap dua dengan lampu $7 \mathrm{~W}$.

\section{Tujuan}

Tujuan Penelitian adalah membangun sirkit sistem 300W yang nantinya sistem tersebut menghasilkan kemampuan untuk;

1. Melayani beban penerangan $7 \times 3 \mathrm{~W}$ selama 15 jam.

2. Melayani beban penerangan $7 \times 7 \mathrm{~W}$ selama 6,5 jam.

\section{TINJAUAN}

\section{Prinsip Kerja Sel Surya}

Sel surya terbuat dari potongan silikon yang sangat kecil dengan dilapisi bahan kimia khusus untuk membentuk dasar dari sel surya. Sel surya pada umumnya memiliki ketebalan minimum 0,3 $\mathrm{mm}$ yang terbuat dari irisan bahan semikonduktor dengan kutub positif dan negatif. Tiap sel surya biasanya menghasilkan tegangan 0,5 volt. Sel surya merupakan elemen aktif (semikonduktor) yang memanfaatkan efek photovoltaic untuk merubah energi surya menjadi energi listrik.

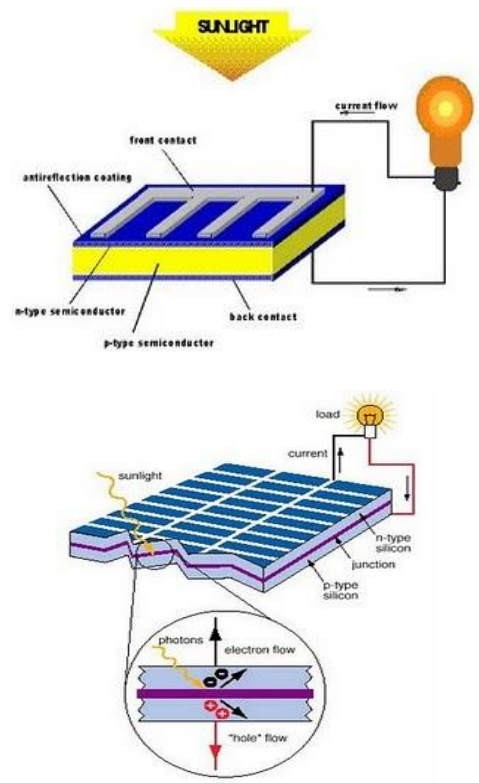

Gambar 2. 1. Diagram kerja sel surya

Pada sel surya terdapat sambungan (junction) antara dua lapisan tipis yang terbuat dari bahan semikonduktor yang masing-masing diketahui sebagai semikonduktor jenis "P" (positif) dan semikonduktor jenis "N" (negatif). Semikonduktor jenis-N dibuat dari kristal silikon dan terdapat juga sejumlah material lain (umumnya posfor) dalam batasan bahwa material tersebut dapat memberikan suatu kelebihan elektron bebas. Elektron adalah partikel sub atom yang bermuatan negatif, sehingga silikon paduan dalam hal ini disebut sebagai semikonduktor jenis-N (negatif). Semikonduktor jenis-P juga terbuat dari kristal silikon yang di dalamnya terdapat sejumlah kecil materi lain (umumnya boron) yang mana menyebabkan material tersebut kekurangan satu elektron bebas. Kekurangan atau hilangnya elektron ini disebut lubang (hole). Karena tidak ada atau kurangnya elektron yang bermuatan listrik negatif maka silikon paduan dalam hal ini sebagai semikonduktor jenis-P (positif).

Susunan sebuah sel surya, sama dengan sebuah dioda, terdiri dari dua lapisan yang dinamakan PN juction. PN junction itu diperoleh dengan jalan menodai sebatang bahan semikonduktor silikon murni (valensinya 4) dengan impuriti yang bervalensi 3 pada bagian sebelah kiri, dan yang di sebelah kanan dinodai dengan impuriti bervalensi 5 . 


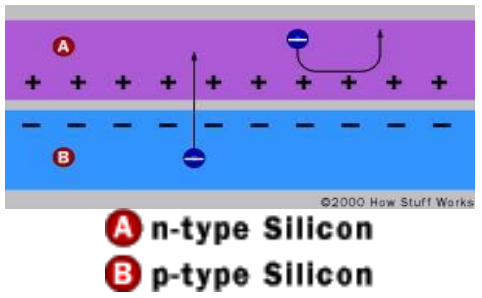

Gambar 2. 2. Efek medan listrik dalam sebuah sel surya

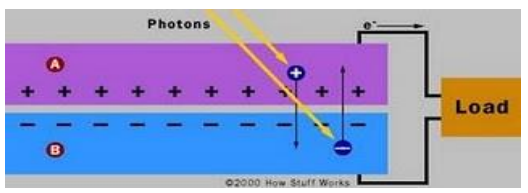

\section{An-type Silicon \\ Bp-type silicon}

Gambar 2. 3. Operasi dari sebuah sel surya

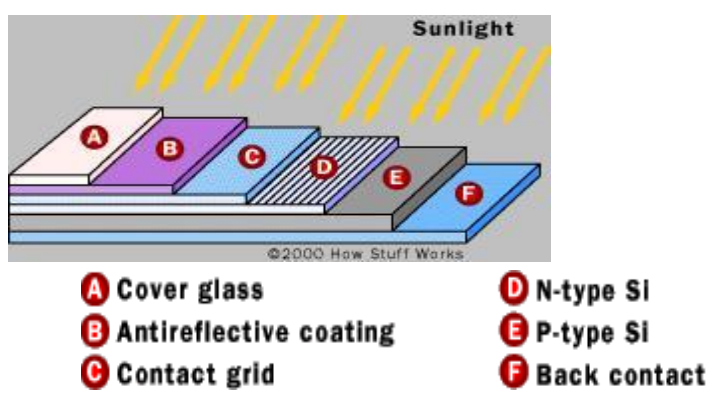

Gambar 2. 4. Struktur dasar dari sebuah sel surya

Sehingga pada bagian kiri terbentuk silikon yang tidak murni lagi dan dinamakan silikon jenis $P$, sedangkan yang sebelah kanan dinamakan silikon jenis N. Di dalam silikon murni terdapat dua macam pembawa muatan listrik yang seimbang. Pembawa muatan listrik yang positif dinamakan hole, sedangkan yang negatip dinamakan elektron. Setelah dilakukan proses penodaan itu, di dalam silikon jenis $\mathrm{P}$ terbentuk hole (pembawa muatan listrik positif) dalam jumlah yang sangat besar dibandingkan dengan elektronnya. Oleh karena itu di dalam silikon jenis $\mathrm{P}$ hole merupakan pembawa muatan mayoritas, sedangkan elektron merupakan pembawa muatan minoritas. Sebaliknya, di dalam silikon jenis $\mathrm{N}$ terbentuk elektron dalam jumlah yang sangat besar sehingga disebut pembawa muatan mayoritas, dan hole disebut pembawa muatan minoritas. Di dalam batang silikon itu terjadi pertemuan antara bagian $\mathrm{P}$ dan bagian $\mathrm{N}$. Oleh karena itu dinamakan PN junction. Bila sekarang, bagian $\mathrm{P}$ dihubungkan dengan kutub positif dari sebuah batere, sedangkan kutub negatifnya dihubungkan dengan bagian $\mathrm{N}$, maka terjadi hubungan yang dinamakan "forward bias".

Pengendali Pengisian

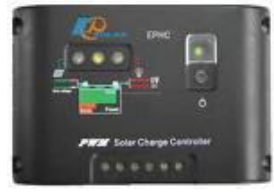

Gambar 2. 2.1.Pengendali Pengisian

Pengendali Pengisian adalah alat yang berfungsi mengontrol proses pengisian energi listrik dari panel surya ke baterai. Pada saat panel surya mendapat energi dari sinar matahari di siang hari, rangkaian Pengendali Pengisian ini otomatis bekerja dan mengisi (charger) baterai dan menjaga tegangan baterai agar tetap stabil. Sebagai contoh jika menggunakan baterai 12 volt, maka rangkaian akan menjaga agar tegangan pengisian 12 volt $\pm 10 \%$, tegangan pengisian yang dibutuhkan antara 13,2 sampai 13,4 volt dan jika telah tercapai tegangan tersebut, rangkaian Pengendali Pengisian otomatis akan menghentikan proses pengisian baterai tersebut. Sebaliknya apabila tegangan baterai turun hingga 10,8 volt, maka Pengendali Pengisian akan memutuskan tegangan ke beban sehingga baterai tidak sampai habis terpakai. Secara keseluruhan fungsi dari Pengendali Pengisian ini adalah menjaga agar baterai tidak kelebihan (over charger) dan kehabisan tegangan (under charger) dengan begitu maka umur dari baterai akan bertambah lama. Baterai yang digunakan di penelitian produk terapan ini spesifikasinya adalah $12 \mathrm{~V}$, 60Ah, 1 unit.

\section{Prinsip Pengaturan Tegangan Keluaran Inverter Satu Fasa}

Metode yang paling efisien dalam pengaturan gain (tegangan keluaran) adalah dengan menerapkan kontrol modulasi lebar pulsa (pulse-width modulation) pada inverter. Teknik yang sering digunakan adalah :

1) Single-pulse-width modulation (SPWM)

2) Multiple-pulse-width modulation (MPWM)

3) Sinusoidal pulse-width modulation

4) Modified sinusoidal pulse-width modulation

5) Phase-displacement control

Dalam penelitian produk terapan ini yang akan dipakaiSingle-Pulse-Width Modulation (SPWM).

\section{Single Pulse Width Modulation, SPWM}

Dalam pengaturan modulasi lebar pulsa tunggal, hanya ada satu pulsa setiap setengah siklus (T/2) dan lebar pulsa diubah-ubah untuk mengatur tegangan keluaran inverter. Gambar 2.4.3 menunjukkan pembangkitan sinyal gate dan tegangan keluaran inverter satu fasa jembatan penuh dengan teknik kontrol modulasi lebar pulsa tunggal (SPWM). 


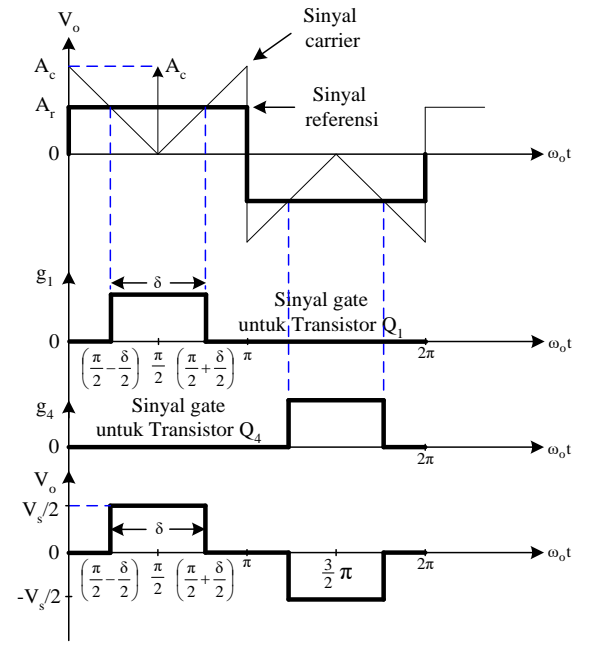

Gambar 2. 4.3.:Modulasi lebar pulsa tunggal

Pada gambar 2.4.3, terlihat saat sinyal referensi terjadi di $0 \mathrm{~s} / \mathrm{d} \pi$, terjadi sinyal gate untuk transistor Q1 sebesar $\delta$ dan untuk sinyal gate transistor Q4, sebesar $\delta$ juga tetapi berada diantara $\pi$ dan $2 \pi$, sehingga terjadi gelombang seperti AC dengan $\delta$ pada setengah gelombang pertama positif antara 0 ke $\pi$ dan $\delta$ pada setengah gelombang kedua negatif antara $\pi$ ke $2 \pi$ sebesar $\delta$ juga, ini merupakan hasil perubahan untuk satu siklus.

\section{Listrik Energi Surya}

Gambar 2.4.4: Rangkaian Inverter

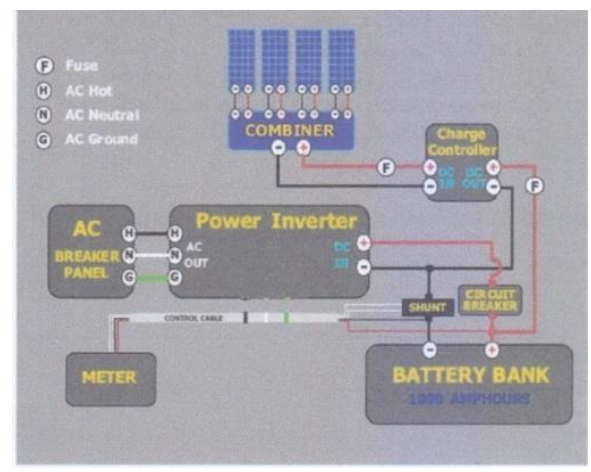

Gambar 2.6. : Diagram Alir Listrik Energi Surya

Energi listrik dari panel surya diatur sedemikian rupa oleh pengendali pengisian untuk disimpan ke baterai dalam bentuk energi kimia. Bila diperlukan energi listrik tersebut dialirkan ke inverter untuk diubah menjadi listrik bolak balik. Listrik bolak balik tersebut siap dipakai untuk kebutuhan sehari-hari. Pada gambar II.6. dapat dilihat aliran daya listrik dan perubahan yang terjadi saat proses perubahan dan penggunaan

\section{TUJUAN}

\section{Tujuan Penelitian}

Tujuan Penelitian adalah mampu membangun system yang mampu mengubah energy surya menjadi energy listrik bolak balik yaitu energy listrik dengan ketentuan $220 \mathrm{~V}, 50 \mathrm{~Hz}$, dengan kemampuan operasional $300 \mathrm{~W}$. Dengan jumlah panel surya 3 lembar atau 6 lembar.

\section{Manfaat Penelitian}

Manfaat Penelitian adalah hasil rancang bangun ini dapat digunakan untuk rumah sederhana untuk kebutuhan penerangan listriknya dengan ketentuan 220V, 50Hz. Dengan beban 7 x 3W selama 15 jam, atau $7 \mathrm{x} 7 \mathrm{~W}$ selama 6,5 jam.

\section{METODE \\ Tahapan-TahapanPenelitian}

- membuat dudukan panel surya,

- menentukan kemiringan panel surya $19^{\circ}$ terhadap Utara,

- menentukan besaran baterai,

- menentukan besaran unit pengendali pengisian baterai,

- menentukan besaran inverter

\section{Parameter PengukurandanPengamatan}

Parameter dan Pengamatan yang dilakukan adalah sebagai berikut,

- tegangan keluaran panel surya,

- arus keluaran panel surya,

- tegangan masukan baterai,

- arus masukan baterai,

- tegangan masukan inverter,

- arus masukan inverter,

- tegangan keluaran inverter,

- arus keluaran inverter,

- tegangan masukan ke beban,

- arus masukan ke beban,

\section{Model Penelitian}

Model Penelitian; rangkaian listrik seri dan paralel dan kombinasi, rangkaian elektronik, penyerap energi surya, kendali pengisian, inverter, penyimpan energi listrik, alat-alat ukur. Hingga menghasilkan energi listrik $300 \mathrm{VA}, 220 \mathrm{~V}, 50 \mathrm{~Hz}$. Sebagai pemberi atau penyedia tenaga listrik untuk beban lampu hemat energi. 


\section{Rancangan Penelitian}

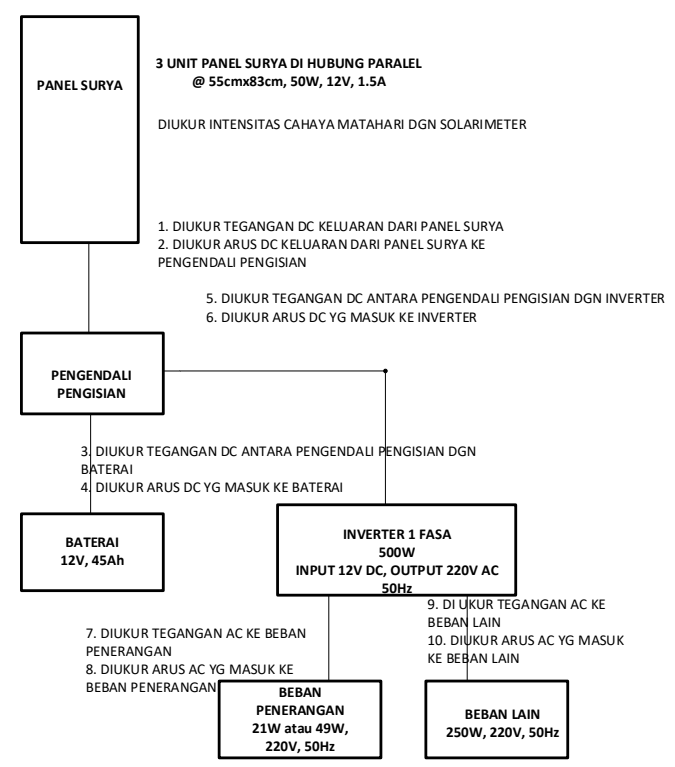

Gambar 4.5.1 : Rancangan Penelitian

Pada gambar 3.5.1, energi listrik yang dihasilkan oleh panel listrik merupakan listrik arus searah, yang dikendalikan oleh pengendali pengisian ke baterai, energi tersebut disimpan di baterai. Saat dibutuhkan energi listrik tersebut keluar dari baterai dan dialirkan ke inverter, selanjutnya dipakai ke masing-masing beban, berupa lampu penerangan sebagai beban prioritas dan alat rumah tangga lain sebagai prioritas berikutnya

Data yang dikumpulkan untuk dianalisis adalah,

- Tegangan keluaran panel surya,

- Arus keluaran panel surya,

- Tegangan antara pengendali pengisian dgn baterai,

- Arus yg masuk ke baterai,

- Tegangan antara pengendali pengisian dgn inverter,

- Arus yg masuk ke inverter,

- Tegangan keluaran inverter yg ke beban penerangan,

- Arus dari inverter ke beban penerangan,

- Tegangan keluaran inverter ke beban lain,

- Arus dari inverter ke beban lain,

Data yang telah diperoleh diamati kepantasannya dan kepatutan maupun kelayakannya. Sebagai suatu sistem terpadu apakah termasuk baik, efisiensinya. Kita membandingkan harga-harga tersebut bila dilakukan dengan energi listrik dari PLN (Perusahaan Listrik Negara).

\section{HASIL DAN LUARAN YANG DICAPAI}

\subsection{Saat Beban Nol}

Saat Beban Nol yaitu saat lampu tidak dihidupkan dan ketiga unit panel surya yang diparalel dilepas dari pengatur pengisian, sehingga yang terbaca hanya tegangan luaran panel surya saja, tegangan rata-rata yang terukur adalah $15-17 \mathrm{~V}$.

\subsection{Saat Pengisian Baterai}

Saat Pengisian Baterai sirkit terpasang lengkap dan ketiga unit panel surya terhubung ke pengendali pengisian hanya beban lampu tidak dinyalakan. Pada saat matahari cerah instrument ukur diamati. Terlihat tegangan luaran rata-rata $15-16 \mathrm{~V}$. Dan arus luaran panel surya rata-rata 4,5-5,4A. Setelah 6 jam diperkirakan arus yang masuk ke baterai 30Ah. Kapasitas baterai 45Ah, artinya harus dilanjutkan lagi keesokan harinya karena agar baterai penuh harus ditambah 15Ah lagi, atau penjemuran panel surya selama 3 jam lagi untuk memenuhi kapasitas penuh baterai sebesar $45 \mathrm{Ah}$. Total pengisian baterai hingga penuh $9 \mathrm{jam}$.

\subsection{Saat Berbeban 7 lampu $3 W 860$ Lumen 220V 50Hz.}

\subsubsection{Saat berbeban 7 lampu $3 W 860$ Lumen $220 \mathrm{~V}$ $50 \mathrm{~Hz}$ Di saat matahari cerah.}

Hasil pengamatan yang diperoleh,

- Tegangan luaran 3 panel surya yang diparalel ratarata $15-17 \mathrm{~V}$

- Arus luaran 3 panel surya yang diparalel rata-rata 4,5-5,4A

- Tegangan antara pengendali pengisian dgn baterai rata-rata 14,04-16V

- Arus yg masuk ke baterai rata-rata 4,5-5,4A

- Tegangan antara pengendali pengisian dgn inverter rata-rata $13-14,04$

- $\quad$ Arus yg masuk ke inverter rata-rata $1,6-1,75 \mathrm{~A}$

- Tegangan keluaran inverter yg ke beban penerangan rata-rata $215-220 \mathrm{~V}$

- Arus dari inverter ke beban penerangan rata-rata $0,09 \mathrm{~A}$

Di siang hari saat matahari cerah untuk 7-8 lampu dapat menyala terus menerus hingga sore.

5.3.2. Saat berbeban 7 lampu $3 \mathrm{~W} 860$ Lumen $220 \mathrm{~V}$ $50 \mathrm{~Hz}$ Di saat malam hari.

Hasil pengamatan yang diperoleh, 
- Tegangan luaran 3 panel surya yang diparalel ratarata $0 \mathrm{~V}$

- Arus luaran 3 panel surya yang diparalel rata-rata $0 \mathrm{~A}$

- Tegangan antara pengendali pengisian dgn baterai rata-rata $0 \mathrm{~V}$

- Arus yg masuk ke baterai rata-rata $0 \mathrm{~A}$

- Tegangan antara pengendali pengisian dgn inverter rata-rata $13-14,04$

- Arus yg masuk ke inverter rata-rata 1,6-1,75A

- Tegangan keluaran inverter yg ke beban penerangan rata-rata $215-220 \mathrm{~V}$

- Arus dari inverter ke beban penerangan rata-rata 0,09A

Di malam hari untuk 7-8 lampu dapat menyala terus menerus dan mampu bertahan hingga 15 jam.

5.3.3. Saat berbeban 7 lampu $3 W 860$ Lumen $220 \mathrm{~V}$ $50 \mathrm{~Hz}$ Di saat matahari kurang cerah, redup, mendung,

Hasil pengamatan yang diperoleh,

- Tegangan luaran 3 panel surya yang diparalel ratarata $0 \mathrm{~V}$

- Arus luaran 3 panel surya yang diparalel rata-rata $0 \mathrm{~A}$

- Tegangan antara pengendali pengisian dgn baterai rata-rata $0 \mathrm{~V}$

- Arus yg masuk ke baterai rata-rata $0 \mathrm{~A}$

- Tegangan antara pengendali pengisian dgn inverter rata-rata $13-14,04$

- Arus yg masuk ke inverter rata-rata 1,6-1,75A

- Tegangan keluaran inverter yg ke beban penerangan rata-rata $215-220 \mathrm{~V}$

- Arus dari inverter ke beban penerangan rata-rata $0,09 \mathrm{~A}$

Di saat maahari kurang cerah , redup, mendung 7-8 lampu dapat menyala, namun sejak mendung terjadi, 7-8 lampu dapat menyala terus hingga baterai lemah, namun dapat bertahan hingga 8 jam dimulai saat mendung terjadi

\section{KESIMPULAN}

1. Sistem yang dibangun disiapkan untuk sistem listrik energi surya hingga 300VA 220V 50Hz. Waktu untuk pengisian baterai hingga $45 \mathrm{Ah}$ dibutuhkan waktu 9 jam.

2. Untuk beban 7-8 unit lampu 3W 860 Lumen $220 \mathrm{~V} 50 \mathrm{~Hz}$ pada siang hari dapat menyala terus seharian saat matahari cerah, demikian juga untuk 7-8 unit lampu 7W 860 Lumen.
3. Untuk beban 7-8 unit lampu $3 \mathrm{~W} 860$ Lumen $220 \mathrm{~V} 50 \mathrm{~Hz}$ pada malam hari dapat menyala hingga 15 jam, namun untuk 7-8 unit lampu $7 \mathrm{~W} 860$ Lumen pada malam hari dapat menyala 8 jam.

4. Untuk beban 7-8 unit lampu 3W 860 Lumen $220 \mathrm{~V} 50 \mathrm{~Hz}$ pada saat matahari kurang cerah, redup, mendung lampu tersebut mampu menyala dan bertahan hingga 8 jam mulai mendung terjadi, namun untuk 7-8 unit lampu 7W 860 Lumen hanya bertahan sekitar 3,5 jam.

5. Efisiensi sistem listrik energi surya memang masih rendah sekitar 0,14

\section{DAFTAR PUSTAKA}

[1]. Anwar Ilmar Ramadhan, Ery Diniardi, Sony Hari Mukti, 2016., Analisis Desain Sistem Pembangkit Listrik Tenaga Surya, Universitas Muhammadiyah Jakarta.

[2]. Miller-Malinoski, 2013., Power System Operation, Mc Graw-Hill, Third Edition.

[3]. PUIL., 2010., Peraturan Umum Instalasi Listrik..

[4]. Rashid, Muhammad H., 2014., Power Electronics

Circuits, Devices, And Applications, Third Edition,

Prentice Hall.

[5]. S.Widodo, 2015., Merakit Pembangkit Listrik

Tenaga Surya Untuk Rumah Tangga, Prosiding

Seminar, Udayana, Den Pasar, Bali. 